\title{
O TEATRO ADMINISTRADO NA SOCIEDADE UNIDIMENSIONAL
}

Leonardo Augusto Madureira de Castro ${ }^{1}$

Isabella Fernanda Ferreira ${ }^{2}$

\begin{abstract}
Resumo:
Marcuse busca lançar luz ao esclarecimento da sociedade administrada a qual vivemos e a qual ninguém é capaz de se inserir sem afetação. Apesar de ser um grande defensor da Arte e, naturalmente, do Teatro, Marcuse nos aponta os vestígios da industrialização daquela, vestígios estes dos quais o Teatro não está imune e pelos quais também é modificado, instrumentalizado e administrado, uma vez que em seu processo de produção atende à mencionada sociedade administrada. A partir de uma rápida revisão bibliográfica dos textos de Marcuse e de autoras e autores como Chaves, Teodoro e Esteves, pode-se perceber a constante busca pela emancipação do Teatro desta sociedade unidimensional, ao mesmo tempo que a Arte é levada a se subjugar aos comandos da industrialização da cultura. Para isso é necessário, entender o conceito de administração e de pensamento unidimensional proposto por Marcuse para enfim compreender como o frankfurtiano percebe tais lapsos nas produções artísticas.
\end{abstract}

Palavras-chave: Teatro. Marcuse. Unidimensionalização. Administração.

\section{THE THEATER MANAGED IN THE UNIDIMENSIONAL SOCIETY}

\begin{abstract}
:
Marcuse seeks to shed light on the enlightenment of the managed society to which we live and which no one is able to insert without affectation. In spite of being a great defender of the Art and, of course, of the Theater, Marcuse points us the vestiges of the industrialization of that one, traces of these of which the Theater is not immune and by which also it is modified, instrumentalized and administered, since in its process to the aforementioned managed company. From a quick bibliographical revision of the texts of Marcuse and of authors and authors like Chaves, Teodoro and Esteves, one can perceive the constant search for the emancipation of the Theater of this one-dimensional society, at the same time that Art is led to subjugate to the commands of the industrialization of culture. For this, it is necessary, to understand the concept of management and one-dimensional thinking proposed by Marcuse to finally understand how the Frankfurdian perceives such lapses in artistic productions.
\end{abstract}

Keywords: Theater. Marcuse. Unidimensionalization. Administration.

Quando pensamos em arte e sociedade não podemos desvincular os processos de construção paralelos de ambos. O estudante de arte e o de sociedade sempre se depara com pontos em comum em que um contribui na coordenação e no esclarecimento do outro. Quando

1 Leonardo Augusto Madureira de Castro é ator e arte educador, graduado em Artes Cênicas e Dança pela Universidade Estadual de Mato Grosso do Sul (UEMS) e mestre em Educação Social pela Universidade Federal de Mato Grosso do Sul (UFMS/CPAN). E-mail: leodecastro92@gmail.com

2 Isabella Fernanda Ferreira é Doutora em Educação pela UNESP de Araraquara. Docente Permanente do programa de Pós-graduação em Educação da UFMS/CPAN. Docente Colaboradora no Programa de Pósgraduação em Educação da UFMS/FAED. Uma das fundadoras e também coordenadora na Rede Nacional/Internacional de Pesquisa "NEXOS Teoria Crítica e Pesquisa Interdisciplinar" dividida pelas cinco regiões do País. Líder do "NEXOS Teoria Crítica e Pesquisa Interdisciplinar - Centro-Oeste/Norte". Membro como pesquisadora do Consórcio Internacional de Programas de Teoria Crítica organizado pela Filósofa Judith Butler. E-mail: bella.fernandaferreira@gmail.com 
se busca o conceito de Pensamento Unidimensional desenvolvido por Marcuse (1973) em sua obra "A ideologia da sociedade industrial: o homem unidimensional" nos deparamos com estes pontos. Para Marcuse (1973), as repressões estão unidas à cultura capitalista, e essa mesma cultura é responsável pela sociedade industrializada, o que leva os sujeitos a aceitarem a sua condição, o que ele explica ao criar o conceito de "Pensamento Unidimensional". A sociedade industrializada em que vivemos tem influência direta no pensamento dos seres humanos, à medida que eles aceitam ser controlados por ela.

Tal nível de pensamento unidimensionalizado, segundo o autor, dá-se pelo racionalismo exacerbado criado para organizar e administrar a sociedade de maneira totalitária. Ele interpreta o conceito como uma racionalidade irracional da sociedade (MARCUSE, 1973), que se prende em seus próprios paradigmas. Esses paradigmas acabam sendo disseminados também pela mídia de massas. No teatro, essas mídias podem auxiliar no processo de 'unidimensionalização' do pensamento quando não ocorre, por exemplo, uma preocupação com a pesquisa estética da arte teatral e da temática pretendida. Nessa nossa sociedade administrada, todos os pensamentos, ideais, ideias e até mesmo ideologias políticas servem a um propósito e, portanto, não são dotadas de neutralidade. Quando encaramos esse propósito como subserviência, constatamos ainda mais o sentido da instrumentalização desses termos que são, por consequência, administradores do pensamento humano. Todos temos ideais, ideias, ideologias e pensamentos objetivados, racional ou subjetivamente.

Esta instrumentalização pode ser observada em todas as vertentes artísticas. Discutiremos aqui, neste artigo, como o teatro também é administrado por esta sociedade unidimensional.

\section{Do Teatro racionalizado e administrado}

A racionalização e os processos administradores do teatro podem ser analisados por meio dos conceitos de pensamento unidimensional e sociedade administrada, propostos por Marcuse (1973). O pensamento unidimensional é o tipo de pensamento racional que se desenvolve por ações de uma sociedade industrial, cujos sistemas todos convertem para a doutrinação do pensamento dos sujeitos. O frankfurtiano conceitua os sujeitos como sendo homens unidimensionais, justamente por viverem e perpetuarem a sociedade unidimensional fazendo parte dela e, ainda mais, fomentando a sua expansão e manutenção. Os produtores do pensamento unidimensional são aqueles que lucram com a vida industrializada e aqueles que

\begin{tabular}{|l|l|l|l|l|}
\cline { 2 - 5 } & Ano 8 & n. 14 & Janeiro-Julho 2019 & p. $183-199$ \\
\hline
\end{tabular}


dela usufruem (ou melhor, são manipulados por ela).

O pensamento unidimensional é sistematicamente promovido pelos elaboradores da política e seus provisionadores de informação em massa. O universo da palavra, dêstes e daqueles, é povoado de hipóteses autovalidadoras que, incessante e monopolisticamente repetidas, se tornam definições ou prescrições hipnóticas. (MARCUSE, 1973, p. 44).

Tudo na sociedade unidimensionalizada converge, segundo Marcuse (1973), para a sua perpetuação. O autor apropria-se do termo "administrado" para explicar tais relações, porque a sociedade é administrada conforme os valores e ideologias da sociedade industrializada massificadora que, por sua vez, mantém-se como hegemonia dominante, não dando suporte algum para que o indivíduo nela inserido deixe de fazer parte dessa malha reificadora. Esse tipo de administração é dado em nível ideológico, o que converge para o pensamento em todos os campos sociais pertencentes às sociedades. Tamanho é o seu poder que, além das estruturas sociais, atinge a intimidade, a subjetividade e o pensamento do ser unidimensionalizado, indivíduo que, por ter sido tão afetado, deixa de ser indivíduo autônomo e passa a pensar conforme as regras estabelecidas pela sociedade, sem perspectivas de novos horizontes. $\mathrm{Ou}$ seja, a sociedade industrializada obriga o indivíduo a usar antolhos, mantendo-o com uma visão, um pensamento, uma ação, uma opinião política, uma vida unidimensional.

Ainda segundo o mesmo autor, esse processo se dá pela industrialização de todos os bens e serviços sociais, assim como na produção da arte. Tal industrialização dicotomiza as reais necessidades daquelas inventadas pela indústria, cegando o consumidor, fazendo-o acreditar que precisa dos produtos culturais oferecidos por essa hegemonia. E isso se dá ao infinito. Quanto mais ela produz bens reificadores, mais ela unidimensionaliza a sociedade, mais ela é programada racionalmente para se manter, ou seja, mais reforça o seu caráter administrador.

A sociedade industrial recente aumentou, em vez de reduzir, a necessidade de funções
parasitárias e alienadas (para a sociedade em seu todo, se não mesmo para o indivíduo). Os
anúncios, as relaçães públicas, a doutrinação e o obsoletismo planejado não mais são custos
improdutivos gerais, mas elementos dos custos básicos de produção. Para ser eficaz, tal produção
de desperdício socialmente necessário exige a racionalização contínua - a utilização incessante
de técnicas avançadas e ciência. [...] A produtividade crescente do trabalho cria um crescente
produto excedente que, quer particular, quer centralmente destinado e distribuído, permite um
consumo aumentado - não obstante o desvio aumentado da produtividade. Enquanto prevalecer
essa constelação, ela reduzirá o valor de uso da liberdade, não havendo razão alguma para insistir
na autodeterminação se a vida administrada fôr confortável e até "boa". (MARCUSE, 1973, p.
63).

Essa paralisia do pensamento só acontece porque o indivíduo se acostumou à "boa vida" mencionada por Marcuse (1973). Em seu livro "A ideologia da sociedade industrial: o homem

\begin{tabular}{|c|c|c|c|c|}
\hline Qevista Dialectus & Ano 8 & n. 14 & Janeiro - Julho 2019 & p. $183-199$ \\
\hline
\end{tabular}


unidimensional", o autor explica que quem é contrário à sociedade pode muito bem ser excluído e rechaçado por ela.

[...] no período contemporâneo, os controles tecnológicos parece serem a própria personificação da Razão para o bem de todos os grupos e interêsses sociais - a tal ponto que tôda contradição parece irracional e tôda ação contrária parece impossível.

Não é, portanto, de admirar que, nos setores mais desenvolvidos dessa civilização, os contrôles sociais tenham sido introjetados a ponto de até o protesto individual ser afetado em suas raízes. A negativa intelectual e emocional de "prosseguir" parece neurótica e impotente. (MARCUSE, 1973, p. 30).

O processo de controle mantém-se totalitário, onipotente e onipresente. O homem unidimensionalizado aceita com impensada facilidade participar desse sistema. Torna-se uma engrenagem dele. "Em sua fase mais avançada, a dominação funciona como administração. E nas áreas superdesenvolvidas de consumo em massa, a vida administrada se torna a boa vida de todos [...].” (MARCUSE, 1973, p. 234).

\begin{abstract}
A perda das liberdades económicas e políticas que foram as conquistas reais dos dois séculos passados pode parecer pequeno dano num Estado capaz de tornar a vida administrada segura e confortável. ${ }^{3}$ Se os indivíduos estão satisfeitos a ponto de se sentirem felizes com as mercadorias e os serviços que lhes são entregues pela administração, por que deveriam 186les insistir em instituições diferentes para a produção diferente de mercadorias e serviços diferentes? E se os indivíduos estão precondicionados de modo que as mercadorias que os satisfazem incluem também pensamentos, sentimentos, aspirações, por que deveriam desejar pensar, sentir e imaginar por si mesmos? É bem verdade que as mercadorias materiais e mentais oferecidas podem ser ruins, extravagantes, imprestáveis - mas Geist ${ }^{4}$ e conhecimento não são argumentos eficazes contra a satisfação das necessidades. (MARCUSE, 1973, p. 63-64, grifo do autor, nota nossa).
\end{abstract}

Esse é o precursor da possibilidade dessa sociedade. Marcuse (1973) deixa claro que o indivíduo "gosta" de ser manipulado.

Provavelmente não se percebe, por enquanto, a fragilidade ideológica, a malha de sistemas que leva o ser humano a um único comportamento de massa (mesmo dentro das mais variadas 'tribos'). Para explicar o fenômeno, Marcuse (1973) utiliza-se dos avanços tecnológicos e da apropriação da natureza, incluindo a humana, pela ciência:

[...] a tecnologia se tornou o grande veículo de espoliação - espoliação $\mathrm{cm}$ sua forma mais madura e eficaz. A posição social do indivíduo e sua relação com os demais não apenas parecem

\footnotetext{
3 (Nota original) Ver p. 24.

4 Espírito, mente.
}

\begin{tabular}{|c|c|c|c|c|}
\hline Q Povista Dialectus & Ano 8 & n. 14 & Janeiro - Julho 2019 & p. $183-199$ \\
\hline
\end{tabular}


determinadas por qualidades e leis objetivas, mas também essas leis e qualidades parecem perder seu caráter misterioso e incontrolável; aparecem como manifestações calculáveis da racionalidade (científica). O mundo tende a tornar-se o material da administração total, que absorve até os administradores. A teia da dominação tornou-se a teia da própria Razão, e esta sociedade está fatalmente emaranhada nela. E os modos transcendentes de pensar parece transcenderem a própria Razão. (MARCUSE, 1973, p. 162, grifo do autor).

Quando a dominação da administração total transcende a razão, o autor explica que surge uma nova forma de prisão, a alteração dos sentidos de racionalidade e irracionalidade. Essa alteração conceitual emaranha o pensamento do indivíduo em uma rede burocrática que, apesar de ter sido desenvolvida para facilitar a vida de todos, aprisiona o indivíduo em processos que dificultam a sua existência.

\begin{abstract}
A sociedade unidimensional em desenvolvimento altera a relação entre o racional e o irracional. Contrastado com os aspectos fantásticos e insanos de sua irracionalidade, o reino do irracional se torna o lar do realmente racional - das Ideias que podem "promover a arte da vida". Se a. sociedade estabelecida controla tôda comunicação normal, validando-a ou invalidando-a de conformidade com as exigências sociais, então os valôres estranhos a essas exigências podem talvez não ter qualquer outro meio de comunicação a não ser o meio anormal da ficção. (MARCUSE, 1973, p. 227).
\end{abstract}

Talvez a arte livre, como menciona o autor, esteja subjugada a tais condições, mas, como arte livre, é negação, resistência. Promove ações para buscar sair das zonas controladas pela administração unidimensional. Mas a guerra ideológica mascara-se na falsa democracia em que vivemos.

\begin{abstract}
Inegàvelmente, uma administração totalitária pode promover a exploração eficiente dos recursos; o estabelecimento nuclear-militar pode garantir emprêgo a milhões por meio de enorme poder aquisitivo; a labuta e as úlceras podem ser o subproduto da aquisição de riqueza e responsabilidade; erros e crimes mortais por parte dos líderes podem ser meramente o estilo de vida. Pode-se estar disposto a admitir a loucura econômica e política - e se compra essa loucura. A tolerância do pensamento positivo é tolerância imposta - [...] pelo poder e eficiência esmagadores e anônimos da sociedade tecnológica. Como tal, ela permeia a consciência geral e a consciência da crítica. A absorção do negativo pelo positivo é validada na experiência diária, que obscurece a distinção entre aparência racional e realidade irracional. (MARCUSE, 1973, p. 209-210).
\end{abstract}

Apesar de o obscurantismo afetar a cultura, ainda há possibilidades de se produzir e se encontrar a cultura superior. Chaves e Ribeiro (2014) avaliam:

A arte pode ser revolucionária em vários sentidos. Em sentido restrito, quando apresenta uma mudança radical no estilo e na técnica (vanguarda), "antecipando ou refletindo mudanças

\begin{tabular}{|l|l|l|l|l|}
\cline { 2 - 4 } & Ano 8 & n. 14 & Janeiro-Julho 2019 & p. $183-199$ \\
\hline
\end{tabular}


substanciais na sociedade" (Marcuse, 1977/1999, p. 12) ${ }^{5}$, como aconteceu com o expressionismo e o surrealismo, que "anteciparam a destrutividade do capitalismo monopolista" (p. 12). Mas também [...] em sua configuração estética, quando apresenta ausência de liberdade do existente e indica as forças que se rebelam contra isso; quando rompe com a realidade reificada e aponta horizontes de transformação; quando subverte as formas de percepção e compreensão e deixa transparecer um teor de verdade, de protesto e de promessa na linguagem e na imagem. (CHAVES et al., 2014, p.14-15).

Para Marcuse (1973), ainda existe certa esperança para a arte, mas os vestígios da arte superior estão pouco a pouco sendo engolidos pela besta reificadora da sociedade capitalista. Isso porque a realidade está, até certo ponto, em um estado além da sua própria cultura.

O que está ocorrendo agora não é a deterioração da cultura superior numa cultura de massa, mas a refutação dessa cultura pela realidade. A realidade ultrapassa sua cultura. O homem [...] resolveu muitos problemas insolúveis. Mas também traiu as esperanças e destruiu a verdade que eram preservadas nas sublimações da cultura superior. Na verdade, a cultura superior estêve sempre em contradição com a realidade social [...]. As duas esferas antagônicas da sociedade sempre coexistiram; a cultura superior sempre foi acomodativa, enquanto a realidade raramente foi perturbada por seus ideais e sua verdade. (MARCUSE, 1973, p. 69-70).

Para ilustrar o seu pensamento, Marcuse (1973) apropria-se da discussão sobre a música de sua contemporaneidade, já quase que universalmente reificada, para tratar do contexto "arte" em geral. Não nos cabe analisar a música em si, mas é bem provável que a administração da música contemporânea tenha o mesmo intuito, até bem mais que nos anos 1970.

Se as comunicações em massa misturam harmoniosamente e, com freqüência, imperceptivelmente, arte, política, religião e filosofia com anúncios, levam essas esferas da cultura ao seu denominador comum - a forma de mercadoria. A música da alma é também a música da arte de vender. O que importa é o valor de troca, e não o da verdade. Em tôrno dele gira a racionalidade do status quo, e tôda racionalidade alienígena se submete a êle. (MARCUSE, 1973 , p. 70, grifo do autor).

Segundo o frankfurtiano, existem ainda os neoconversadores, que acreditam que é válida e benéfica a apropriação da arte pela indústria. O capital acaba, segundo Marcuse (1973, p. 76-77), transformando a possibilidade de aproximação cultural das pessoas em uma ótima oportunidade para mudar a ideologia de tais obras, por analogias e instrumentalização, para outros fins, em geral comerciais. A racionalização em favor do lucro em relação à obra artística a faz aproximar-se de seu público, mas ela já se aproxima sofrendo intervenções, tanto em sua produção quanto em sua finalidade.

5 Marcuse, H. A dimensão estética (M. E. Costa, Trad.). Portugal: Ed. 70, (Original publicado em 1977) 1999.

\begin{tabular}{|c|c|c|c|c|}
\cline { 2 - 5 } & Rovista & Jialectus & Janeiro-Julho 2019 & p. $183-199$ \\
\hline
\end{tabular}




\begin{abstract}
É bom o fato de quase todos podem ter atualmente as belas-artes ao seu alcance, simplesmente ligando o seu receptor ou entrando numa loja. Contudo, elas se tornam, nessa difusão, dentes de engrenagem de uma máquina de cultura que refaz seu conteúdo. A alienação artística sucumbe, juntamente com outras formas de negação, ao processo de racionalidade tecnológica. A modificação revela sua profundidade e o grau de sua irreversibilidade quando vista como um resultado do progresso técnico. (MARCUSE, 1973, p. 76-77).
\end{abstract}

Concordando com o autor, a ordem estabelecida tem o poder de alienar a arte em sua forma mais pura, para transformá-la. A arte propicia que o indivíduo enxergue a sua realidade com outros olhos. "A alienação artística é a transcendência consciente da existência alienada uma alienação de "nível superior" ou interposta" (CHAVES et al. apud MARCUSE, 2014, p. 20-21), sendo assim, "Essa alienação é emancipatória: “Alienação de uma sociedade alienada, em virtude da qual ela se dissocia metodicamente daquela e cria o universo [...] em que se [...] expressa a verdade" (Kangussu, 2010, p. 207) ${ }^{6}$." (CHAVES et al., 2014, p. 16). Arte, para Marcuse (1973), é negação.

Na verdade, a alienação não é a única característica da arte. [...] O lugar da obra de arte numa cultura pré-tecnológica e bidimensional é muito diferente do que numa civilização unidimensional, mas a alienação caracteriza tanto a arte afirmativa como a negativa. A distinção decisiva não é a psicológica entre arte criada na alegria e arte criada na tristeza [...] mas entre realidade artística e realidade social. O rompimento com a segunda [...] é uma qualidade essencial até mesmo da arte mais afirmativa [...] A "cultura superior" em que essa alienação é notória tem seus próprios ritos e seu próprio estilo. [...] (MARCUSE, 1973, p. 74-75).

Tais estilos são aqueles que, como cultura superior, buscam em sua forma, e principalmente em seu conteúdo, possibilidades de uma representação desalienante. Marcuse (1973) relembra Brecht e sua relação ideológica, conferindo ao teatro o conceito de "Teatro Político".

\begin{abstract}
Bertolt Brecht esboçou os fundamentos teóricos para esses esforços. O caráter total da sociedade estabelecida confronta o dramaturgo com a questão sobre se ainda é possível representar o mundo contemporâneo no teatro" - isto é, representa-lo de tal modo que o espectador reconheça a verdade que a peça se destina a transmitir. Brecht responde que o mundo contemporâneo só pode ser assim representado se é representado como sujeito a modificação ${ }^{7}$ - como o estado de negatividade que deve ser negado. [...] mas o teatro é e deve ser divertimento e prazer. Contudo, divertimento e aprendizado não são opostos; o divertimento pode ser uma das maneiras mais eficazes de se aprender. [...] Não são necessários empatia e sentimento, mas distância e reflexão. (MARCUSE, 1973, p. 77-78).
\end{abstract}

6 KANGUSSU, I. Marcuse, vida e arte. In HADDOCK-LOBO, R. (Org.), Os filósofos e a arte. Rio de Janeiro: Rocco, p. 205-219, 2010.

7 (Nota original) Bertolt Brecht. Schriffen zum Theater (Berlim e Frankfurt Suhrkamp 1957), pp. 7, 9.

\begin{tabular}{|l|l|l|l|l|}
\cline { 2 - 5 } & Ano 8 & n. 14 & Janeiro-Julho 2019 & p. $183-199$ \\
\hline
\end{tabular}


Marcuse (1973) explica o excerto em que cita Brecht, demonstrando o que aquele chama de "função" da Arte, ao definir os objetivos da arte em uma sociedade irracional.

\begin{abstract}
A ênfase dada à relação entre arte e técnica indica a racionalidade específica da arte.
[...] a arte cria outro universo de pensamento e prática contra o existente e dentro dêle. Mas, em contraste com o universo técnico, o universo artístico é de ilusão, aparência, Schein ${ }^{8}$. Contudo, essa aparência é semelhança com uma realidade que existe como a ameaça e a promessa da realidade estabelecida. ${ }^{9}$ Em várias formas de máscara e silêncio, o universo artístico é organizado pelas imagens de uma vida sem temor - de máscara e em silêncio porque a arte não tem podêres para criar essa vida e até mesmo para representá-la adequadamente. [...] Quanto mais espetacularmente irracional se torna a sociedade, tanto maior a racionalidade do universo artístico. (MARCUSE, 1973, p. 220, grifo do autor, nota nossa).
\end{abstract}

O autor evidencia hipóteses para a racionalidade da arte, propondo ser "[...] visualizada como validada pela transformação científico-tecnológica do mundo e funcionando nela." (MARCUSE, 1973, p. 221), reduzindo assim os sistemas reificadores da sociedade administrada.

Segundo Hegel ${ }^{10}$, a arte reduz a contingência imediata na qual um objeto (ou uma totalidade de objetos) existe, para um estado no qual o objeto assume a forma e a qualidade de liberdade. Tal transformação é redução porque a situação contingente sofre exigências que são externas e que se interpõem à sua livre realização. Essas exigências constituem um "aparato", visto como não são meramente naturais, mas, antes, sujeitas a modificação e a desenvolvimento livres e racionais. Assim, a transformação artística viola o objeto natural, mas o violado é, êle próprio, opressivo; assim, a transformação estética é libertação. (MARCUSE, 1973, p. 220-221).

Entendemos como Teatro racionalizado e administrado aquele que é pensado de modo unidimensionalizado para o alcance de um determinado fim, seja ele pedagógico, ideológico, artístico ou puramente prazeroso. Este Teatro é calculado de modo que, tanto quem o produz, quanto quem o apreende, se tornem sujeitos (ativos e passivos) de uma "doutrinação" que, por sua vez, é baseada no fim para o qual o Teatro foi planejado. Marcuse (1973), em seu livro "A ideologia da sociedade industrial", no primeiro capítulo "As novas formas de controle", já avalia como a sociedade, com sua razão, cultura e ideologia, torna-se administrada pelos

8 Nesse caso, pode ser traduzido como "máscara".

9 (Nota original) Ver capítulo 3.

10 (Nota original) Hegel. Vorlesungen über die Aesthetik, em Sâmtliche Werk, ed. H. Glockner (Stuttgart, Frommann, 1929), vol. XII, pp. 217 e seg. Ver também a tradução de Osmaston, em Hegel, The Philosophy of Fine Art (Londres, Bell and Sons, 1920), vol. I, p. 214.

\begin{tabular}{|l|l|l|l|l|}
\cline { 2 - 5 } & Ano 8 & n. 14 & Janeiro-Julho 2019 & p. $183-199$ \\
\hline
\end{tabular}


processos de industrialização social, que é cada vez mais ensimesmada, vítima e algoz de sua própria reificação.

Uma falta de liberdade confortável, suave, razoável e democrática prevalece na civilização industrial desenvolvida, um testemunho de progresso técnico. De fato, o que poderia ser mais racional do que a supressão da individualidade na mecanização de desempenhos socialmente necessários, mas penosos [...]? (MARCUSE, 1973, p. 23).

A falta de liberdade é até percebida, mas, por ora, é forte demais para ser combatida. $\mathrm{O}$ cerceamento de outras possibilidades sociais é conjuntura para que o homem se mantenha preso a um pensamento totalitário em si mesmo. Essa completude não o torna autônomo. Muito pelo contrário, afasta-o de sua emancipação como indivíduo de uma sociedade administrada. Ele não tem tempo para sentir, humanizar-se, o que determina os processos de reificação ainda mais comuns.

\begin{abstract}
Quanto mais racional, produtiva, técnica e total se torna a administração repressiva da sociedade, tanto mais inimagináveis se tornam os modos e os meios pelos quais os indivíduos administrados poderão romper sua servidão e conquistar sua própria libertação. Sem dúvida, a idéia de impor a Razão a uma sociedade inteira é paradoxal e escandalosa - embora se possa discutir a correção de uma sociedade que ridiculariza essa idéia enquanto transforma sua população em objetos de administração total. Tôda libertação depende da consciência de servidão e o surgimento dessa consciência é sempre impedido pela predominância de necessidades e satisfações que se tornaram, em grande proporção, do próprio indivíduo. O processo substitui sempre um sistema de precondicionamento por outro; o objetivo ótimo é a substituição de falsas necessidades por outras verdadeiras, o abandono da satisfação repressiva. (MARCUSE, 1973, p. 28).
\end{abstract}

Marcuse (1973) denuncia o medo e a sombra com que a sociedade industrial afeta o indivíduo, o sujeito, coisifica o subjetivo e prende-o em uma trama econômico-social da qual é impossível escapar.

Defrontamos novamente com um dos aspectos mais perturbadores da civilização industrial desenvolvida: o caráter racional de sua irracionalidade. Sua produtividade e eficiência, sua capacidade para aumentar e disseminar comodidades, para transformar o resíduo em necessidade e a destruição em construção, o grau com que essa civilização transforma o mundo objetivo numa extensão da mente e do corpo humanos tornam questionável a própria noção de alienação. As criaturas se reconhecem em suas mercadorias; encontram sua alma em seu automóvel, $h i$-fi, casa em patamares, utensílios de cozinha. O próprio mecanismo que ata o indivíduo à sua sociedade mudou, e o contrôle social está ancorado nas novas necessidades que ela produziu. (MARCUSE, 1973, p. 29-30. Grifo do autor).

Sendo assim, como explica o autor, as necessidades não são mais necessidades, pois são

\begin{tabular}{|l|l|l|l|l|}
\cline { 2 - 4 } & Ano 8 & n. 14 & Janeiro-Julho 2019 & p. $183-199$ \\
\hline
\end{tabular}


criadas a partir de pressupostos não inerentes a todo ser humano. A sociedade industrializada passa por constantes atualizações, que a mantêm afastada do desenvolvimento emancipatório de seus membros. Uma fragmentação é imposta pela unidimensionalidade do pensamento, ou seja, pelo modo de produzir do homem com propósitos administrados para a manutenção de um sistema que gera a espoliação dos sujeitos pelos próprios sujeitos. Tudo gira em torno da vontade do sistema de se manter como dono do indivíduo, ou seja, transformando-o em coisa, para, assim, manipulá-lo a seu bel prazer.

O aparato produtivo e as mercadorias e serviços que êle produz "vendem" ou impõem o sistema social como um todo. Os meios de transporte e comunicação em massa, as mercadoras casa, alimento e roupa, a produção irresistível da indústria de diversões e informação trazem consigo atitudes e hábitos prescritos, certas reações intelectuais e emocionais que prendem os consumidores mais ou menos agradàvelmente aos produtores e, através dêstes, ao todo. Os produtos doutrinam e manipulam; promovem uma falsa consciência que é imune à sua falsidade. E, ao ficarem êsses produtos benéficos à disposição de maior número de indivíduos e de classes sociais, a doutrinação que êles portam deixa de ser publicidade; torna-se um estilo de vida. É um bom estilo de vida - muito melhor do que antes - e, como um bom estilo de vida, milita contra a transformação qualitativa. Surge assim um padrão de pensamento e comportamento unidimensionais no qual as idéias, as aspirações e os objetivos que por seu conteúdo transcendem o universo estabelecido da palavra e da ação são repelidos pela racionalidade do sistema dado e de sua extensão quantitativa. (MARCUSE, 1973, p. 32, grifo do autor).

O teatro que, ideologicamente, luta contra isso, também cai nas malhas obscuras do pensamento unidimensional, à medida que não é produzido nem recebido de modo a refletir essas mudanças de paradigmas sociais. O que também faz jus ao que Marcuse (1973) explicita quando aborda questões sobre o pensamento unidimensional. Trata-se de "[...] uma sociedade na qual tanto os sujeitos como os objetos constituem instrumentos num todo que tem a sua razão de ser nas realizações de sua produtividade cada vez mais poderosa.” (MARCUSE, 1973, p. 42).

É justamente aí que se justifica a instrumentalização do Teatro. Ele é projetado e administrado para amenizar os efeitos secundários da industrialização social e, ao sê-lo, acaba por se tornar um meio, um instrumento, uma simples ferramenta. Como ferramenta, o Teatro não muda nada, apenas perpetua esse mal-estar. Vira escravo dos escravos da civilização industrial que, assim como eles, possui as mesmas características, pois o Teatro se transforma e modifica segundo o ser humano se transforma e se modifica. Do mesmo modo que o Teatro é reificado e, por isso, administrado com fins específicos na sociedade, quem o promove dessa maneira é também reificado, como uma engrenagem que gira a outra. "Esta é a forma pura de servidão: existir como um instrumento, como uma coisa." (MARCUSE, 1973, p. 49)

\begin{tabular}{|c|c|c|c|c|}
\cline { 2 - 5 } & Ano 8 & n. 14 & Janeiro-Julho 2019 & p. $183-199$ \\
\hline
\end{tabular}


No pensamento marcuseano, é inadmissível aceitar o Teatro como engrenagem de uma sociedade industrial porque Teatro é Arte. De acordo com Chaves e Ribeiro (2014):

Para Marcuse, a arte é política, apresenta universalidade, alteridade, transcendência, forma estética e negação e confirmação da realidade. A arte é objetivação e não trabalho alienado, ela realiza a sublimação e provoca sensibilidade, diferenciando-se da mercadoria que se apropria da cultura, fazendo-a esvaziar-se em seu sentido. (CHAVES et al., 2014, p. 12).

O Teatro é, talvez, a Arte mais humanizada e humanista, que melhor expressa os sentimentos do ser social e coloca todos os sistemas em xeque. Porém, o Teatro é feito por humanos, e por consequência, acaba se tornando voz da ideologia dos homens. Em uma sociedade industrializada, a produtividade, a mercadoria, o lucro é a ideologia.

Desde que correspondam à realidade em questão, o pensamento e o comportamento expressam uma falsa consciência, reagindo à preservação de uma falsa ordem dos fatos e contribuindo para ela. E essa falsa consciência se corporificou no aparato técnico prevalecente, o qual, por sua vez, a reproduz. [...] Contudo, o aparato derrota o seu próprio objetivo se êste é criar uma existência humana com base numa natureza humanizada. E se êsse não é o seu propósito, sua racionalidade se torna ainda mais suspeita. Mas ela é também mais lógica porque, de início, o negativo está no positivo, o desumano está na humanização, a escravização na libertação. Essa dinâmica é a da realidade e não da mente, mas de uma realidade na qual a mente científica teve papel decisivo em unir a razão teórica e prática. (MARCUSE, 1973, p. 142-143).

Uma dinâmica dialética que acaba se perdendo com o pensamento unidimensionalizado, ou seja, que mantém uma única dimensão, na qual, não se distingue humano de coisa, Teatro de ferramenta.

Nesse universo, a tecnologia também garante a grande racionalização da não-liberdade do homem e
demonstra a impossibilidade "téenica" de a criatura ser autônoma, de determinar a sua própria vida. Isso
porque essa não-liberdade não parece irracional nem política, mas antes uma submissão ao aparato técnico
que amplia as comodidades da vida e aumenta a produtividade do trabalho. [...] A dinâmica incessante do
progresso técnico se tornou permeada de conteúdo político e o Logos da técnica foi transformado em
Logos da servidão contínua. A fôrça libertadora da tecnologia - a instrumentalização das coisas - se torna
o grilhão da libertação; a instrumentalização do homem. (MARCUSE, 1973, p. 154-155, grifo do autor).

O progresso técnico da sociedade invade e subjuga até o momento mais pessoal e humano de alguém, reifica seu pensamento, condiciona seus desejos e suas ideias de necessidade para algo que não lhes é intrinsicamente necessário. Surge nesse contexto, a arte unidimensionalizada, pensada e produzida sem distinguir meios de fins, sem criar novas possibilidades de pensamento e de crítica. Nos questionamos em como é possível que a Arte

\begin{tabular}{|l|l|l|l|l|}
\cline { 2 - 5 } & Ano 8 & n. 14 & Janeiro-Julho 2019 & p. $183-199$ \\
\hline
\end{tabular}


seja administrada desta maneira, ou seja, como ela foi subjugada por um pensamento reificador e por quem foi subjugada. Marcuse (1973) busca a resposta apontando a disseminação deste controle aos mais poderosos que esta sociedade pode criar.

O pensamento unidimensional é sistemàticamente promovido pelos elaboradores da política $\mathrm{e}$ seus provisionadores de informação em massa. O universo da palavra, dêstes e daqueles, é povoado de hipóteses autoavaliadoras que, incessante e monopolìsticamente repetidas, se tornam definições ou prescrições hipnóticas. (MARCUSE, 1973, p. 34).

Estes manipuladores da política e das informações de massa agravam a disseminação do pensamento unidimensionalizado ao repetirem diariamente as ideologias, reforçando-as com os produtos que ela mesma produz. Esta sociedade produz produtos alienantes e ao distribuílos contribuem para sua reprodução.

Esteves (2010), em sua dissertação de mestrado, sobre a obra de Marcuse, vê-se uma preocupação com o conceito de mimese, comum aos estudos teatrais, no qual, o ser humano, por imitação compreende e se adapta ao mundo.

É este sentido de mimese mais próximo à ideia de adaptação ao mundo para conquista da autopreservação, de ser dominado pelo mundo a partir da adaptação a ele, que Marcuse lança mão em One-dimensional man.

No primeiro capítulo de seu livro, Marcuse articula a produção e a distribuição de mercadorias em massa mediante a eficácia tecnológica com a produção de falsas necessidades superimpostas a átomos sociais manipulados sob a sociedade totalitária não-terrorista e argumenta que o resultado foi a absorção dos indivíduos pela realidade. Mais que "introjetar" da sociedade industrial avançada para si, os indivíduos se identificam com ela: há uma "mimese: uma identificação imediata do indivíduo com a sua sociedade e, através dela, com a sociedade em seu todo"12. (ESTEVES, 2010, p. 106, grifo do autor).

Por outro lado, conforme Ferreira (2015), a mimese faz parte da constituição da arte:

Toda expressão artística, independente da sua natureza e do tempo histórico na qual está inserida a sua produção, necessita de dois elementos que são imanentes à sua constituição: a mimese e a racionalidade. A mimese se refere diretamente à manifestação da subjetividade do artista e à racionalidade ao modo como ele organiza tecnicamente toda a sua irracionalidade. Nessa relação,

11 (Nota original) 0 termo introjeção supõe a existência de uma dimensão psíquica separada e mesmo antagônica à dimensão exterior e subentende a existência de uma liberdade interior. Porém, Marcuse argumenta que a realidade tecnologia invadiu e desbastou a dimensão interior, anulando o "Eu" e retirando dele o poder crítico da razão. MARCUSE, H. One-dimensional man: studies in: The ideology of advanced industrial Society. 2o printing. London/New York: Routledge, 2002, p. 12.

12 (Nota original) MARCUSE, H. Mimesis: na immediate identification of the individual with his Society and, through it, with the Society as a whole. Ibidem, p. 12.

\begin{tabular}{|c|c|c|c|c|}
\hline Revirta Aldectus & Ano 8 & n. 14 & Janeiro - Julho 2019 & p. $183-199$ \\
\hline
\end{tabular}


a técnica se constitui o elemento de mediação entre a mimese e a racionalidade dos artistas no momento da produção de suas obras.

Conforme Adorno $(1988)^{13}$, esses dois elementos constitutivos na produção de uma obra artística devem se manifestar em uma relação dialética de permanente tensão, ou seja, não deve imperar nenhum elemento de maneira absoluta sobre o outro para que a obra produzida consiga ser verdadeiramente expressiva.

A garantia da permanência da tensão dialética entre os elementos miméticos e racionais na produção de uma obra de arte se apresenta cada vez mais obstaculizada pela problemática social a que Adorno e Horkheimer (1985) denominaram de indústria cultural. (FERREIRA, 2015, p. 335-336).

Esta problemática enfatiza processos de depreciação da memória artística da obra de arte em si. Já não se conhece mais as origens das obras e sim sua constituição atual dentro de uma sociedade industrializada. E isso, por si só, já desvincula a arte de seu propósito, incluindo o da mimese, ou seja, a de também ser recordação. Chaves e Ribeiro (2014) explicam: A arte preserva a recordação, que é o solo no qual ela tem a sua origem. Decorre, então, a
necessidade de a imaginação deixar aparecer o outro (possível). A decepção e a aparência são
qualidades da realidade, antes de o serem da arte. A arte, no entanto, não encobre essas
dimensões, mas as revela. A verdade da obra consiste na ilusão evocada, na insistência em criar
um mundo no qual o terror da vida é recordado e interrompido. (CHAVES et al., 2014, p. 17).

É intrínseco à Arte o olhar para os fatos (bons e ruins) que acontecem em nossa sociedade. Parece-nos, que até esta característica, a da mimese, ajuda o ser social a apreender melhor sua realidade. O que a torna muito mais difícil de combater, principalmente por ser mais uma engrenagem do pensamento unidimensional, que propõe o Teatro, a mimese, para conversar com os problemas sociais em comum e, ao fazê-lo, reinventar o que já está inventado. Este reinvento do que não é necessário são as falsas necessidades acusadas por Marcuse (1973).

Para Marcuse, a produção e a distribuição, tecnológicas e eficazes, de falsas necessidades, mimetizam os átomos sociais com a sociedade industrial avançada e ensejaram uma realidade unidimensional prescrevendo os hábitos que eles devem ter, oferecendo-lhes um estilo de vida que veicula a realidade unidimensional. Assim, esta não é somente reflexo da etapa monopolista do capitalismo, a realidade unidimensional é, ela mesma, o modo pelo qual a ordem se mantém [...]. (ESTEVES, 2010, p. 107-108).

Em seu livro "Eros e Civilização", Marcuse (1975) traz um panorama filosófico sobre a obra de Freud para demonstrar inclusive que a lógica da dominação está presente por ações

13 Adorno, T. W. (1988). Teoria estética. Lisboa: Edições 70.

\begin{tabular}{|c|c|c|c|c|}
\cline { 2 - 5 } & Ano 8 & n. 14 & Janeiro-Julho 2019 & p. $183-199$ \\
\hline
\end{tabular}


humanas de dominação de todo o conteúdo humano, incluindo a libido, o prazer tanto carnal quanto metafísico, as relações humanas, tudo, tudo faz parte da lógica da dominação, inclusive a própria razão, o próprio pensar racional. Marcuse explica:

A razão tem por finalidade garantir, através de uma transformação e exploração cada vez mais efetiva da natureza, a realização das potencialidades humanas. Mas, no processo, a finalidade parece recuar diante dos meios: o tempo dedicado ao trabalho alienado absorve o tempo para as necessidades individuais - e define as próprias necessidades. O Logos destaca-se como a lógica de dominação. Assim, quando a lógica reduz as unidades de pensamento a sinais e símbolos, as leis do pensamento convertem-se, finalmente, em técnicas de cálculo e manipulação. (MARCUSE, 1975, p. 108).

O tempo destinado à transformação do homem e à elevação das coisas do espírito mais uma vez é anulado pela lógica da dominação. O Teatro em si é por fim pensado com lógica, mas com a lógica da manipulação, tanto do tempo despendido, quanto da sua finalidade, tanto do modo como os profissionais da educação se dispõem a trabalhar o Teatro na escola quanto dos processos de criação propostos. Tudo está, segundo Marcuse (1975) dominado pela sociedade industrializada. Em "Eros e Civilização", Marcuse (1975) desenvolve uma ideia de que a Arte poderia ser a reconciliadora entre o Eros e o Logos, entre espírito e matéria.

Certo, há um modo de trabalho que oferece um elevado grau de satisfação libidinal, cuja execução é agradável. E o trabalho artístico sempre que genuíno parece brotar de uma constelação instintiva não-repressiva e visar finalidades não-repressivas tanto assim que o termo sublimação parece requerer considerável modificação se o aplicarmos a esse gênero de trabalho. (MARCUSE, 1975, p. 88).

Neste livro, Marcuse (1975) ainda buscava entender a Arte como potencializadora da denúncia contra a sociedade unidimensionalizada. Faz isso partindo do princípio que o prazer que a Arte proporciona ao ser humano contém em seu princípio formas transformadoras da razão, contra a reificação do ser humano, à favor de sua humanização partindo de sua capacidade de sentir prazer, ao mesmo tempo que combatia o trabalho da indústria cultural.

\footnotetext{
Os grupos e os ideais grupais, as filosofias, as obras de arte e literatura que ainda expressam, sem transigências, os temores e esperanças da humanidade, situam-se contra o princípio de realidade predominante; constituem a sua absoluta denúncia. (MARCUSE, 1975, p. 102).
}

Por fim, entende inclusive a Arte, ao mesmo tempo, como ponto dinâmico de emancipação e da unidimensionalidade do pensamento.

\begin{tabular}{|c|c|c|c|c|}
\cline { 2 - 5 } Govista & Ano 8 & n. 14 & Janeiro-Julho 2019 & p. $183-199$ \\
\hline
\end{tabular}


A arte é, talvez, o mais visível retorno do reprimido, não só no indivíduo, mas também no nível histórico-genérico. A imaginação artística modela a memória inconsciente da libertação que fracassou, da promessa que foi traída. Sob o domínio do princípio de desempenho, a arte opõe à repressão institucionalizada a imagem do homem como um sujeito livre; mas num estado de nãoliberdade, a arte só pode sustentar a imagem da liberdade na negação da não-liberdade. Desde o despertar da consciência de liberdade, não existe uma só obra de arte autêntica que não revele o conteúdo arquetípico: a negação da não-liberdade. (MARCUSE, 1975, p. 135)

E o repete, buscando "saídas" também em seu ensaio "A arte na sociedade unidimensional" quando introduz seu texto com timidez, mas firmeza quando afirma que a Arte

[...] é na verdade a única linguagem revolucionária que hoje nos resta.

Isso pode soar romântico, e muitas vezes me censuro por ser talvez demasiado romântico em avaliar o poder radical, libertador da arte. [...] Entretanto, a sobrevivência da arte pode vir a ser o único elo frágil que hoje conecta o presente com a esperança do futuro. (MARCUSE, In: LIMA, 2000, p. 259-260).

Marcuse (2000) nos indica o potencial da arte como promotora da emancipação da sociedade mecanizada. Marcuse ainda explica:

\begin{abstract}
A fim de que se faça mais claro o que estou querendo dizer, discuto em primeiro lugar em que sentido a arte é uma faculdade cognitiva dotada de uma verdade intrínseca e em que sentido a linguagem da arte revela uma verdade oculta e reprimida. Sugerirei que a arte, em sentido extremo, fala a linguagem da descoberta. (MARCUSE, In: LIMA, 2000, p. 263).
\end{abstract}

Porém o próprio Marcuse (1975), em “A ideologia da sociedade industrial”, desenvolve a ideia de que até a Arte se subjuga e que a própria subjetividade alcançada por ela tenha sido unidimensionalizada. Em "Eros e Civilização", Marcuse (1975) em suas análises, demonstra que a Arte sempre se fazia forte e potente no campo das ideias e dos ideais das obras de arte, mas que dificilmente persuadiria o todo social (industrializado) para repensar sua ideologia.

A arte desafia o princípio de razão predominante; ao representar a ordem da sensualidade, invoca uma lógica tabu a lógica da gratificação, contra a da repressão. Subentendido na forma estética sublimada, o conteúdo não-sublimado transparece: a vinculação da arte ao princípio de prazer. A investigação das raízes eróticas da arte desempenha um importante papel na Psicanálise; contudo, essas raízes estão mais na obra e função da arte do que no artista. (MARCUSE, 1975, p. 165).

Marcuse (1975) já apresentava essa dificuldade da Arte em extrair da obra esse princípio do prazer que por ventura seria de grande relevância nas possibilidades de "saídas" da sociedade

\begin{tabular}{|c|c|c|c|c|}
\hline Qovista Dialectus & Ano 8 & n. 14 & Janeiro - Julho 2019 & p. $183-199$ \\
\hline
\end{tabular}


unidimensional, e passa a olhar a Arte com outra posição, como nos aponta Teodoro (2012), em "O papel da arte apresentado por Herbert Marcuse em A ideologia da sociedade industrial."

\begin{abstract}
A capacidade da arte de manter viva a perspectiva de realização do princípio de prazer através da dimensão estética e da reconciliação entre espírito e matéria, apresentada anteriormente por Marcuse em Eros e Civilização, é refutada em A ideologia da sociedade industrial por uma primazia total do princípio de realidade que transforma a arte em um mecanismo subjugado às regras da sociedade dominante. Dessa forma, a arte perde sua capacidade de oposição à realidade estabelecida e passa a ser instrumento mantenedor da dominação social. A dimensão estética, antes considerada utópica e subversiva, se vê subjugada à unidimensionalização aparentemente hegemônica, que afeta a sociedade. (TEODORO, 2012, p. 121, grifo do autor).
\end{abstract}

Parece que é preciso ter uma função, é necessário um fim específico para se "utilizar" o Teatro. Pensa-se como administrar a Arte para que esta "sirva a".

\begin{abstract}
Na perspectiva do campo artístico, a premissa anterior da arte como a capacidade de suscitar outra dimensão, mais prazerosa, diferente da realidade, é deixada de lado, pois, na sociedade industrial, até mesmo a imaginação torna-se coisificada. A arte torna-se uso do aparato técnico de dominação, a tecnologia põe a coloca a serviço da ideologia dominante. Dessa forma, o caráter negativo da obra de arte perde-se em meio à positividade da crescente indústria que a transforma em puro entretenimento. (TEODORO, 2012, p. 138).
\end{abstract}

Pensemos adiante para entender esse lugar do Teatro para talvez vislumbrar futuramente outro lugar. Horkheimer (2002) afirma, na conclusão de "Meios e Fins" que:

\begin{abstract}
A filosofia hoje deve enfrentar a questão de se o pensamento pode permanecer senhor de si mesmo nesse dilema e preparar assim a sua solução teórica ou se contentará em exercer o papel de metodologia vazia, apologética ilusória ou receita garantida [...]. (HORKHEIMER, 2002, p. $62)$.
\end{abstract}

Talvez a mesma provocação feita pelo frankfurtiano seja necessária à expressão da Arte que aqui coube análise, sendo possível trocar o termo "filosofia" por "Teatro" neste mesmo excerto. Talvez essa provocação seja necessária inclusive para definir-se de vez ou lançar ainda mais o olhar do Teatro para a obscuridade. Talvez o Teatro tenha voltado para a caverna platônica e está agora sob serviço das projeções que bailam nas paredes da consciência social a que estamos todos nós sujeitos, ou pelo menos na consciência daqueles que estão envolvidos com o ambiente escolar. Esta caverna platônica, por sua vez é todo o aparato industrial que se move, como que fechando cada vez mais a saída desta caverna. É preciso um "brilho" dentro dela para que a Arte, e em consequência o Teatro, produzidos nas salas de aula possam encontrar

\begin{tabular}{|l|l|l|l|l|}
\cline { 2 - 5 } & Ano 8 & n. 14 & Janeiro-Julho 2019 & p. $183-199$ \\
\hline
\end{tabular}


seu caminho de afastamento da reificação. Afastamento que nos termos marcuseanos pode se estabelecer por uma educação que no seu "caminhar" não se preocupe somente com a educação intelectual, mas também, com a educação dos instintos relacionando razão e imaginação.

\section{Referências:}

CHAVES, J.; RIBEIRO, D. Arte em Herbert Marcuse: formação e resistência à sociedade unidimensional. In: Revista Psicologia \& Sociedade, 26(1), 2014, p. 12-21.

ESTEVES, Anderson Alves. Sociedade administrada em Herbert Marcuse. Dissertação de Mestrado em Filosofia. PUC-SP. São Paulo, 2010.

FERREIRA, Isabella Fernanda. A ciber (cultura) e o redimensionamento da experiência (semi)formativa na produção artística de hiper (textos). In: A Psicologia Social e os atuais desafios ético-políticos no Brasil. Porto Alegre: ABRAPSO, 2015, p. 326-345.

MARCUSE, H. A ideologia da sociedade industrial: o homem unidimensional. Rio de Janeiro: Zahar Editores. $4^{\mathrm{a}}$ Ed. 1973.

Eros e civilização: uma interpretação filosófica do pensamento de Freud. Rio de Janeiro. 6 ${ }^{\text {a }}$ Ed. Zahar Editores. 1975.

A arte na sociedade unidimensional. In: LIMA, Luis Costa (Org.). Teoria da Cultura de Massa. $6^{\text {a }}$ edição revista. São Paulo: Editora Paz e Terra, 2000.

A dimensão estética. 1977. Lisboa: Editora 70, 2007.

TEODORO, J. B. F. O papel da arte apresentado por Herbert Marcuse em A ideologia da sociedade industrial. IN: Griot - Revista de Filosofia, Bahia - Brasil, v.5, n.1, 2012.

\begin{tabular}{|l|l|l|l|l|}
\cline { 2 - 4 } & Ano 8 & n. 14 & Janeiro-Julho 2019 & p. $183-199$ \\
\hline
\end{tabular}

